believe that tasting eye drops prevents them taking their medication. Patients could be advised to instil one drop only; this may prevent a swallowing reflex.

In order to prevent passage of drops to the stomach, temporary punctual plugs could be inserted. Another approach would be to avoid drops and instead use orbital floor, subtenon, intravitreal, or sustained release implants.

This study suggests that patients' compliance and concordance with ocular drug treatment may be reduced during the period of Ramadan. These patients may require education and closer monitoring during this period. It should be noted that only three patients consulted their doctor before changing their drop regime. Mosque imams (priests) can play a major role in advising patients and should be educated on this subject.

Islam forbids fasting if this would be harmful to the individual. A person who deliberately puts his health at risk by fasting against the advice of his physician contradicts this basic principle of Islam. Therefore, appropriate advice from a doctor during Ramadan may encourage patients to continue taking their drops and prevent irreversible damage as a result of ocular disease.

N Saha

Specialist Registrar in Ophthalmology, Bradford

Royal Infirmary, Bradford, Yorkshire, UK

Correspondence: N Saha,

144 Newlaithes Road,

Horsforth,

Leeds LS18 4SY, UK

Tel: + 44 77907775085;

Fax: + 4401132589119 .

E-mail: docsaha@yahoo.co.uk

Eye (2007) 21, 878-879; doi:10.1038/sj.eye.6702753;

published online 9 February 2007

Sir,

\section{Unusual chorioretinal defects}

The case report of a child with atypical chorioretinal colobomata is presented. The defects are unusual as they lie along both the superior and inferior maculopapillar bundles and yet a vision of $6 / 5$ is still present.

Colobomas result from incomplete closure of the embryonic fissure around weeks $5-8$ gestation. ${ }^{1}$ Closure starts at the equator and continues anteriorly and posteriorly. Any insult during this time can create defects of varying size and location. Colobomas may extend from the iris margin to the optic disc and involve one or more defects along the fusional lines. Typical colobomas are seen inferonasally.

Atypical colobomas are found outside this area and therefore do not originate in a defect of embryonic fissure closure. They are thought to be either pathogenic in origin or owing to faulty differentiation of ocular structures. ${ }^{2,3}$ Macular colobomas have been described as sharply defined, oval, or round central defects. ${ }^{4}$ Paramacular colobomas are described as solitary oval- or torpedo-shaped chorioretinal lesions located temporal to the fovea in one or both eyes. ${ }^{5}$ Neither accurately describes the colobomas present in this case.

\section{Case report}

A 5-year-old girl presented to us after her first optician's visit. Some areas of retinal pallor (Figure 1) were noted and referred to Eye Clinic. The patient was entirely asymptomatic. There were no developmental concerns raised by the family, she was attending school and doing well. Further questioning revealed a full term pregnancy with no perinatal problems. There was no past medical history and she had never been on any regular medications. There was no family history of note. She had no siblings.

Ocular examination revealed a visual acuity of $6 / 5$ in each eye. No nystagmus was present. Anterior segments, optic discs, and the left fundus were normal. The right fundus had two well-demarcated chorioretinal defects. The edges of the defects gently sloped, demonstrating the thickness of the inner ocular layers down to sclera. The

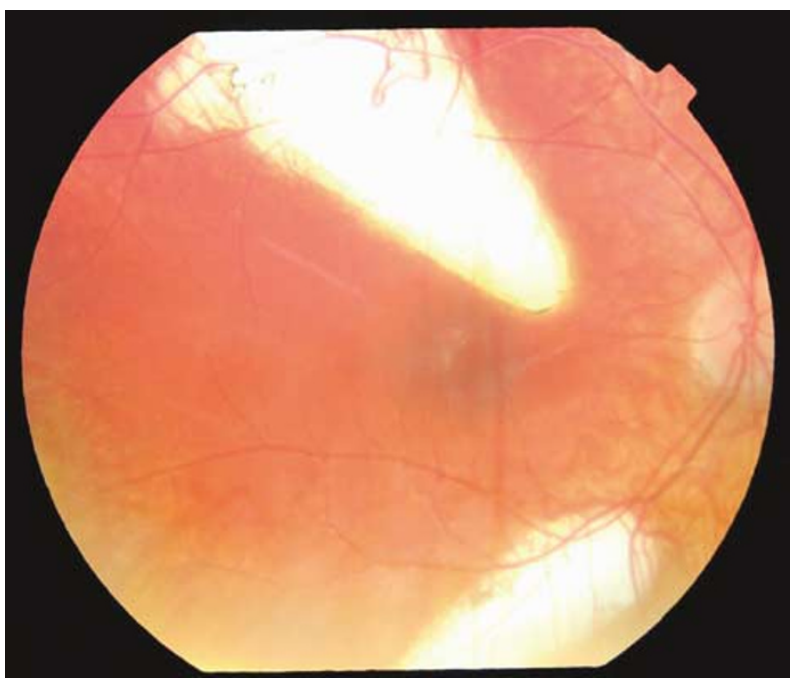

Figure 1 Right fundus photograph. 
two defects were arcuate in nature, above and below the macula. A corresponding scotoma was present.

\section{Comment}

It is rare to see chorioretinal colobomas in these locations. The presence of a normal visual acuity despite such extensive involvement of the maculopapillar bundles is remarkable.

Both retinochoroidal and optic nerve colobomas may be associated with systemic abnormalities. ${ }^{6}$ Abnormalities can affect the central nervous, cardiovascular, genitourinary, musculoskeletal, gastrointestinal, and nasopharyngeal systems. These should be appropriately investigated. Other chorioretinal defects do not require such investigation.

\section{References}

1 Duvall J. Histopathologic study of ocular changes in a syndrome of congenital anomalies. Am J Ophthalmol 1987; 103: 701-705.

2 Mann I. Developmental Abnormalities of the Eye, 2nd ed. Lippincott: Philadelphia, 1957, p 124.

3 Klein BA. The pathogenesis of some atypical colobomas of the choroid. Am J Ophthalmol 1959; 48: 597-607.

4 Mann IC. On certain abnormal conditions of the macular region usually classed as colobomata. Br J Ophthalmol 1927; 11: 99-116.

5 Angioi-Duprez K, Maalouf T. Torpedo maculopathy. J Fr Ophtalmol 2000; 23: 200.

6 Gregory-Evans CY, Williams MJ, Halford S, Gregory-Evans K. Ocular coloboma: a reassessment in the age of molecular neuroscience. J Med Genet 2004; 41: 881-891.

\section{AS Litwin and J Hakim}

Ophthalmology Department, Queen Mary's Sidcup NHS Trust, Sidcup, Kent, UK

Correspondence: AS Litwin, Ophthalmology Department, Queen Mary's Sidcup NHS Trust, Frognal Avenue,

Sidcup,

Kent DA14 6LT, UK

Tel: + 4402083022678 Ext. 4167 or 4182;

Fax: + 4402083083089 .

E-mail: andre@doctors.org.uk

\section{Proprietary interests: None}

No proprietary interests declared. No funding was received.

Eye (2007) 21, 879-880; doi:10.1038/sj.eye.6702754; published online 9 February 2007
Sir,

Primary intraocular lymphoma mimicking multifocal choroiditis and panuveitis

Primary intraocular lymphoma (PIOL) is well known for its mimicry of other ocular diseases and its propensity to evolve. ${ }^{1}$ We managed a patient who presented with a picture of multifocal choroiditis and panuveitis, but subsequently developed more characteristic lesions.

A 73-year-old male had poor vision of the left eye after cataract surgery 4 months earlier. His ophthalmologist had been treating him for cystoid macular oedema.

Examination showed corrected visual acuity of 20/30 right eye and 20/200 left eye. Both eyes had $1+$ anterior vitreous cells. Both fundi showed atrophic pigment epithelial lesions in the mid-periphery (Figure 1). In the right temporal periphery, a tan subretinal lesion was seen and was interpreted as an eccentric disciform scar (Figure 2). The left macula had cystoid oedema (Figure 3).

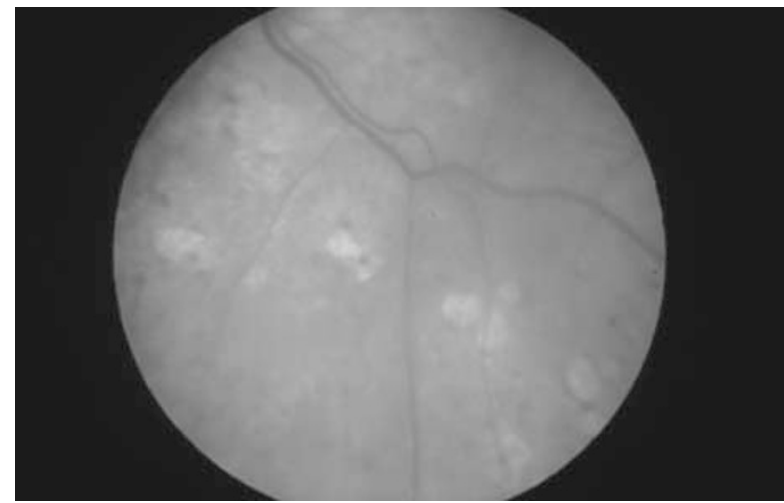

Figure 1 Black and white fundus photograph of the left eye shows atrophic pigment epithelial lesions in the mid-periphery at presentation.

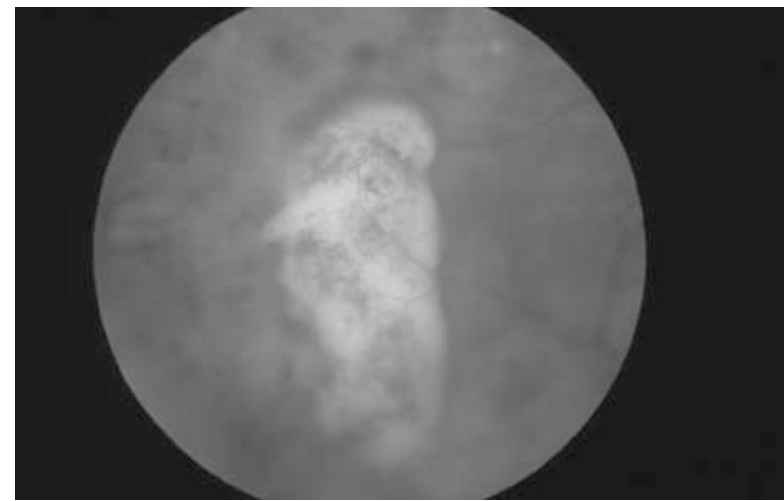

Figure 2 Black and white fundus photograph of the right eye shows a tan subretinal lesion in the right temporal periphery present initially, which was interpreted as an eccentric disciform scar. It later spontaneously resolved. 